\title{
Metastatic Pancreatic Ductal Adenocarcinoma
}

National Cancer Institute

\section{Source}

National Cancer Institute. Metastatic Pancreatic Ductal Adenocarcinoma. NCI

Thesaurus. Code C158960.

An adenocarcinoma that arises from the exocrine pancreatic ducts and has metastasized to other anatomic sites. 